\title{
Spark-Gap Flashover Measurements for Steeply Rising Voltage Impulses
}

\author{
J. H. Park and H. N. Cones
}

(March 19, 1962)

\begin{abstract}
Two designs of thin ribbon resistors have been devised which are suitable for high-voltage surges and have very low time constants $\left(2 \times 10^{-9}\right.$ sec). They were used in making up dividers for measuring linearly rising chopped impulses with peak voltages up to 300 kilovolts and times to sparkover from 0.03 to 50 microseconds. Errors in divider ratio due to residual inductance were found by computation to be less than 1 percent. Stray capacitance errors were kept low by making total divider resistance $1,000 \mathrm{ohms}$ or less. By a combination of computation and experimentation, capacitance errors were deduced to be not greater than 1 percent for times to sparkover 0.1 microsecond or greater.

A large number of oscillograph records were obtained of spark-gap flashover voltage with linearly rising voltage impulses at rates of rise up to 10,000 kilovolts per microsecond. From these oscillograms data were derived giving a relation between rate of rise (or rise time) and flashover voltage for (1) 12.5-cm-diameter spheres spaced $6 \mathrm{~cm}$ apart, (2) 25-cm-diameter spheres spaced $6 \mathrm{~cm}$, and (3) 6.5-inch-diameter uniform field electrodes spaced $5 \mathrm{~cm}$. Volttime curves showing these relations were plotted. It is recommended that the curve for 25-cm-diameter spheres be used as a reference standard for interlaboratory comparison of measurement methods.
\end{abstract}

\section{Introduction}

The measurement of wave form and peak value of a steeply rising voltage impulse is of considerable importance in the testing of high-voltage equipment such as insulators, transformers, and lightning arresters. Such measurements are usually made by impressing the voltage impulse on the high-voltage terminal of a divider consisting of resistors, capacitors, or a combination of both, and connecting the low side of the divider through a coaxial cable to the deflecting system of a cathode ray oscillograph (CRO). For measuring the peak value of full-wave impulses or waves chopped on the tail, the accuracy of dividers is well established, and measurement methods can readily be checked using standardized sphere-gap breakdown tables $[1,2,3] .^{1}$ However, the sphere-gap tables cannot be used for times to sparkover less than $2 \mu$ sec, because for such short times, the sparkover ${ }^{2}$ voltage of sphere gaps increases as time to sparkover decreases giving a volttime curve. This was noted in 1935 by Bellaschi and Teague [4]. Hagenguth [5] has shown that rod gaps and insulator strings also exhibit a volt-time effect.

Several years ago, in AIEE Conference Paper No. $57-215$, the present authors suggested the use of sphere-gap volt-time curves as reference standards for checking measurement methods at times to sparkover less than $2 \mu$ sec. Since that time work reported from other laboratories $[6,7,8,9,10]$ has indicated that such a standard could be useful. The purpose of the present paper is to serve as a permanent published record of the work done several years ago and to present results of later work in this field at the National Bureau of Standards.

1 Figures in brackets indicate the literature references at the end of this paper. 2 The terms sparkover and flashover are assumed to have the same meaning.

\section{Requirements for Setting Up Volt-Time Standards}

Before volt-time curves can be considered for adoption as part of a standard, experimental data must be obtained and published by various laboratories working in the high-voltage field. Conditions under which the data for such curves are obtained must be decided upon, and they should be such that they can be readily duplicated in all laboratories. Ordinary laboratory conditions of temperature, pressure, and humidity should be satisfactory, provided corrections for relative air density are applied. All comparisons can then be made at $760 \mathrm{~mm}$ of $\mathrm{Hg}$ pressure and either 20 or $25{ }^{\circ} \mathrm{C}$ temperature. No applicable corrections for humidity are available, but records should be kept to see if any correlation between humidity and flashover voltage can be detected.

Another condition which must be controlled is the location of the spheres with respect to floor, leads, divider, surge generator, and any other nearby objects. International Electrotechnical Commission Publication 52 entitled "Recommendations for Voltage Measurements by Means of Sphere-Caps (One Sphere Earthed)" contains very deinite specifications for clearance distances when spheres are used for 60-cycle or full-wave voltages. It would seem logical, at first, to adopt these same specifications for front-chopped wave measurements. Also, the effect of changes in such distances should be determined.

In addition to the above, it is necessary to specify wave shape of the applied voltage before chopping. In fact, in all steep-front testing it is extremely important to be able to define waveform exactly and in detail so that results obtained in different laboratories can be accurately compared. This is 
true not only for checking measurement methods, but also for comparing test data on high-voltage equipment. Thus, even though other means are found for checking measurement methods in various laboratories, the task of obtaining an accurately definable wave front must be completed before any steep-front chopped-wave tests will give results which can be repeated in other laboratories.

The presently accepted methods of defining wave front and rate of rise use either the 10 and 90 or 30 and 90 percent voltage points together with some restriction on superposed oscillations. Such definitions pin down only two points on the wave front and give no possibility of fixing tolerances. However, if a linearly rising wave front is defined as one which rises at a constant rate from 30 to 100 percent $^{3}$ of flashover (or breakdown) voltage, any departure from the defined waveform can be determined. Although linearly rising waves, free from oscillations and curvature, are not always readily obtained in practice, they can in all cases be attained to within the required tolerance with a little patience in choosing and adjusting circuit parameters. Since they offer the only possibility of setting up a standard steep-front wave shape which can be accurately duplicated in various laboratories, it is suggested that linearly rising waves be adopted as the standard. This does require setting up an allowable tolerance from an exactly constant rate of rise and devising a practical method for measuring rate of rise at all points from 30 to 100 percent of flashover voltage. Both of these problems are discussed and a solution suggested in appendix $\mathrm{I}$.

The remainder of this paper is devoted to (1) a description of the methods used at the NBS to obtain points on the volt-time curves, (2) an analysis of the accuracy obtained, and (3) a presentation of the results.

\section{Impulse Generator Circuit Arrangements for Obtaining a Linearly Rising Voltage}

The circuit arrangement and general precautions needed to obtain a linearly rising voltage will probably vary considerably for different laboratories. The impulse generator used in the present work has a nominal rating of $2,000 \mathrm{kv}$ when its twenty $1 / 3-\mu$ f capacitor units are connected in series. A modified connection of the 20 units, putting two sections (10 units in series for each) in parallel on discharge, was used in the present work, giving a rated discharge voltage of $1,000 \mathrm{kv}$. The breakdown voltages of the gaps used varied approximately from 140 to $300 \mathrm{kv}$ depending on the rate of voltage rise. Thus, breakdown could always be made to take place on the linearly rising portion of the applied voltage, i.e., much before the knee of the exponential curve.

\footnotetext{
3 (Waveform below the 30 percent voltage point is not considered to be of importance in front-chopped testing because here the phenomenon being studied is dielectric failure for an applied voltage surge of short duration, and the mechanism probably is not initiated until the voltage magnitude approaches the fullwave breakdown value.)
}

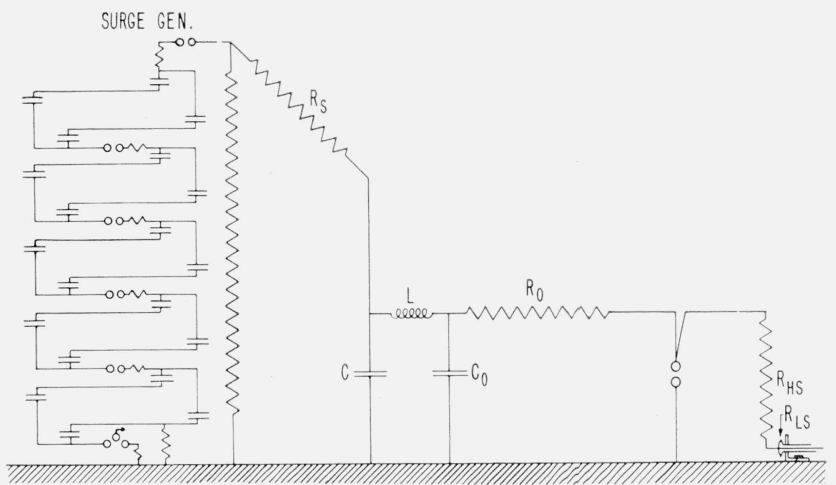

Figure 1. Schematic diagram of impulse generator and discharge circuit used to obtain linearly rising voltages.

A schematic diagram of the impulse generator and discharge circuit arrangement for obtaining various rates of voltage rise is shown in figure 1. Rate of voltage rise was controlled by (1) adjusting the generator charging voltage and/or (2) changing the time constant of the $R-C$ circuit made up of " $R_{s}$ " and " $C$." To keep rate of voltage rise linear up to breakdown, it was found that the charging voltage had to be maintained above about 50 percent of rated value. Thus large changes in rate of rise were made by using wide variation in $R_{s}$ and $C$. Combinations of paper-oil capacitors connected in series were used to give fixed values of $C$ as follows: 0.06 , $0.006,0.003,0.002 \mu \mathrm{f}$ (for steepest rates of rise $C=0)$. $\quad R_{s}$ was made up of double wire-wound card resistors $2 \mathrm{in}$. wide and $12 \mathrm{in}$. long having values of 5 , 15,35 , or 125 ohms each. They were used in series combinations giving values from 35 to 875 ohms. Because of residual inductance in the paper-oil capacitors, $C$ resonates at about $1.3 \mathrm{Mc} / \mathrm{s}$ and produces oscillations on the rising front of the voltage across $C$. The lumped inductance " $L$ " and capacitance " $C_{0}$ " together with " $R_{0}$ " act as a filter to give a smoothly rising voltage at the sphere gap. The inductor $L$ consisted of 100 turns of polyethylene-insulated wire on a 2 -in. diam bakelite tube, giving an inductance of $50 \mu \mathrm{h}$. The capacitor $C_{0}$ consisted of 3 aluminum hemispheres $1 \mathrm{~m}$ in diam, placed with their curved surfaces down and supported by porcelain-pedestal insulators so that the curved surfaces were kept about 8 in. above the conducting floor. The resistor $R_{0}$ consisted of the same type of cards as used for $R_{s}$, its value being held constant at $105 \mathrm{ohms}$ (seven 15-ohm cards in series). Results were obtained with the test gaps at various distances from the aluminum hemispheres in order to study proximity effects.

\section{Measurement-Methods and Dividers}

Resistance dividers in conjunction with a coldcathode CRO [11] were used for all measurements. Several different divider and gap arrangements (as indicated in figs. $2,3,4,5$, and 6 ) were tried to determine possible effects that the location of nearby conductors might have on either gap flashover or 


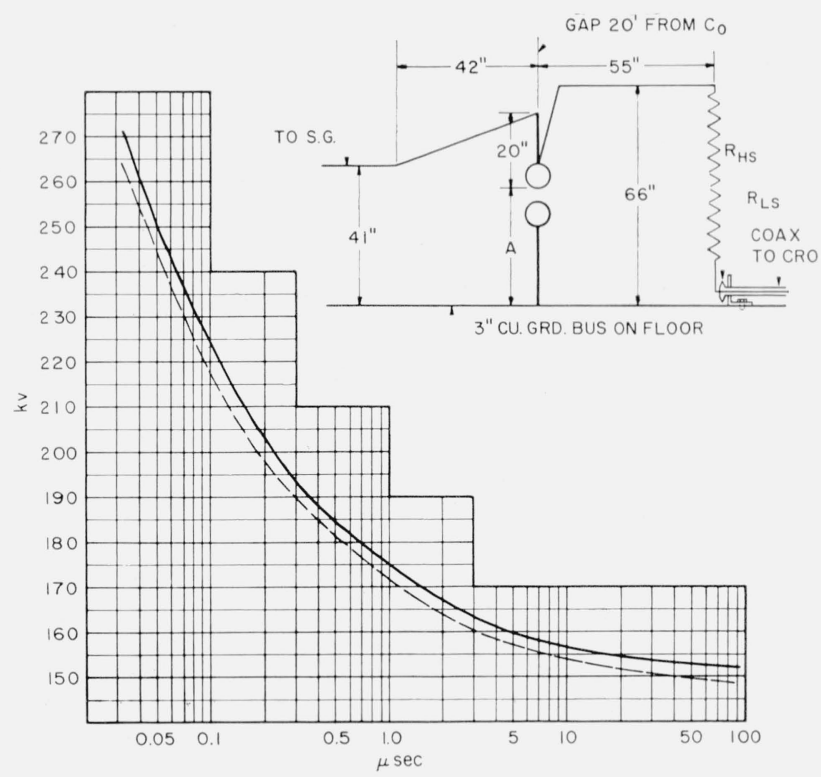

FIGURE 2. Volt-time curve for 12.5-cm spheres spaced $6 \mathrm{~cm}$, upper sphere negative.

All voltages corrected to $760 \mathrm{~mm}$ of $\mathrm{Hg}$ and $25^{\circ} \mathrm{C}$. Solid curve obtained with $A=34$ in. Dashed curve with $A=16$ in. Insert shows sphere gap and divider arrangement. $R_{H S}=1,000$ ohms

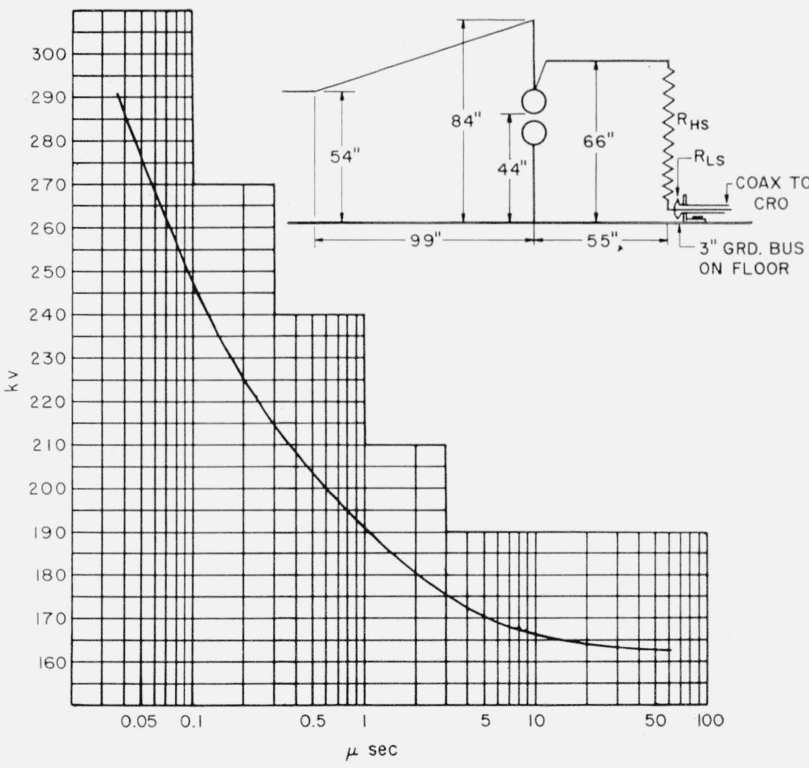

FIgure 3. Volt-time curve for 25-cm spheres spaced $6 \mathrm{~cm}$, upper sphere negative.

All voltages corrected to $760 \mathrm{~mm}$ of $\mathrm{Hg}$ and $25^{\circ} \mathrm{C}$. Insert shows sphere gap and divider arrangement. $R_{H S}=1,000 \mathrm{ohms}$. Other sphere gap and divider arrangements also gave points falling on this curve.

divider response. A $60-\mathrm{ft}$ length of polyethylene coaxial cable $(\mathrm{RG} 8 / \mathrm{U})$ was used for the connection from divider low side to the CRO. The method of terminating this cable at the oscillograph and determining its attenuation correction have been described in a previous publication [12]. A check for possible stray pickup voltage in the measuring circuit was made by using a special cable fitting
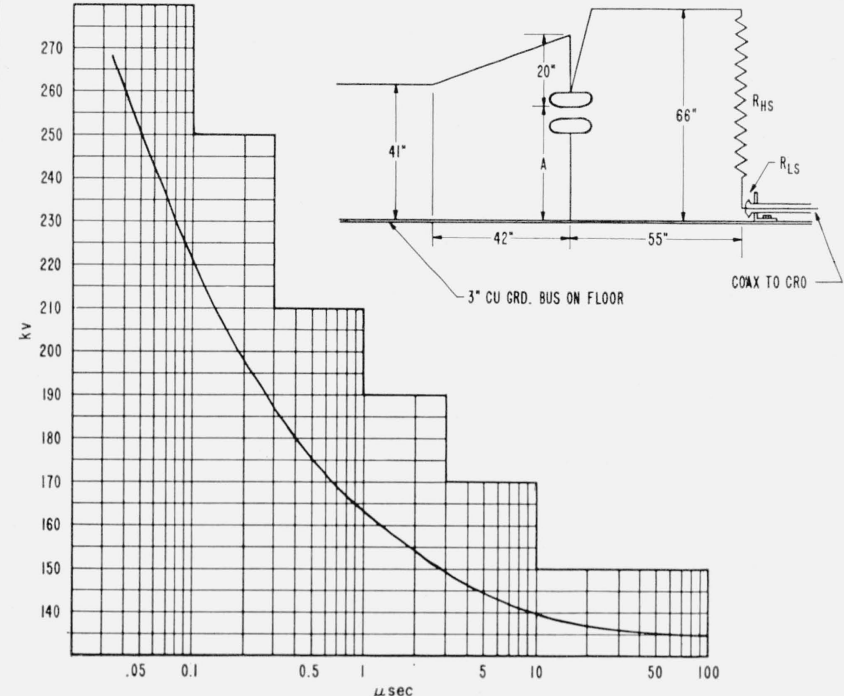

FIGURE 4. Volt-time curve for uniform field gap, spacing $5 \mathrm{~cm}$, upper electrode negative.

All voltages corrected to $760 \mathrm{~mm}$ of $\mathrm{Hg}$ and $25^{\circ} \mathrm{C}$. Insert shows gap and divider arrangement. $R_{H S}=1,000 \mathrm{ohms}$. Points obtained with $A=20$ in. and $A=40$ in. all fall on same curve.
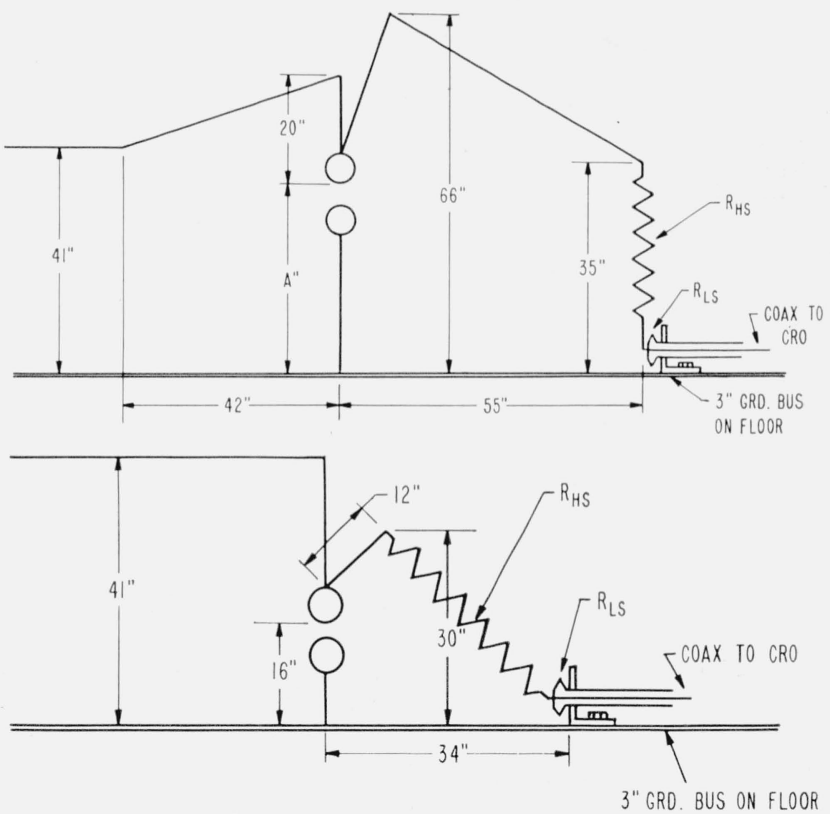

FIGURE 5. Sphere gap and divider arrangements using $\mathrm{R}_{\mathrm{HS}}$ $=500 \mathrm{ohms}(5-100 \mathrm{ohm}$ ribbon-wound cards) with 12.5-cm spheres spaced $6 \mathrm{~cm}$.

(Upper) A. Similar to figure 2 except $R_{H S}=500$.

(Lower) B. With divider very close to spheres.

between the divider low side and the cable to the oscillograph. This fitting offers no discontinuity or asymmetry in the cable sheath, but it disconnects the center conductor of the oscillograph cable from the divider low side and connects it to the cable sheath. With this fitting in place there should be no signal deflection recorded on the oscillograph when the generator is discharged and a voltage applied to the 


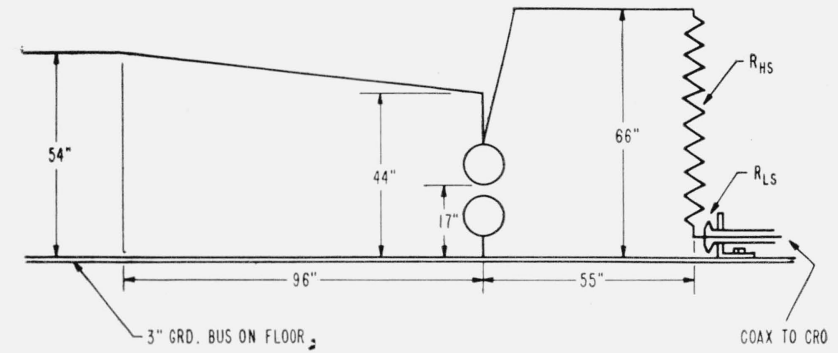

FIGURE 6. Sphere gap and divider arrangement with $25-\mathrm{cm}$ spheres spaced $6 \mathrm{~cm}$.

Spheres close to floor. $R_{H S}=1,000 \mathrm{ohms}$.

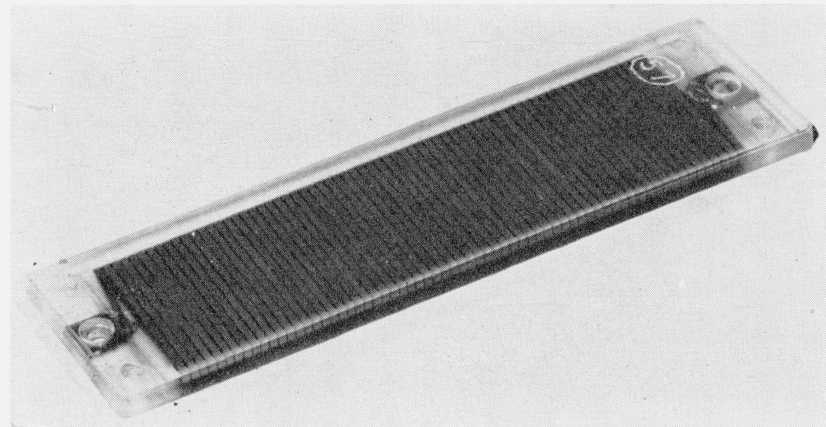

Figure 7. Double-wound card resistor cast in epoxy.

Karma ribbon 1/16 inch wide and 0.001 inch thick with 0.001 inch Teflon between layers. Time constant, $L / R=0.002 \times 10^{-6}$.

divider. Any departures from a straight zero line would indicate pickup in the measuring circuits, probably due to ground currents in the cable sheath, CRO case, etc. Methods of connecting the cable to the oscillograph and arranging ground connections were devised and necessary changes made until this test indicated negligible pickup.

The divider high side $\left(R_{H S}\right.$ of figs. 1 to 6$)$ consisted of five or ten 100 -ohm special Karma ${ }^{4}$ ribbon resistor units. Each unit (see fig. 7) has an overall length of $6 \frac{1}{2}$ in. and consists of two oppositely wound layers of ribbon $(1 / 16 \mathrm{in}$. wide and $0.001 \mathrm{in}$. thick) on a lucite card ( $1 \frac{1}{2}$ in. wide and $1 / 16$ in. thick). Slots were milled in the edges of the lucite cards to keep the turns of ribbon uniformly spaced. The first layer of ribbon was enameled; but since the enamel did not completely cover the edges, a sheet of teflon (0.001 in. thick and $1 \frac{1}{2} \mathrm{in}$. wide) was laid over each side of the lucite card before starting to wind the second layer. A brass mold was specially constructed in which the double wound lucite cards were cast in epoxy resin (epon 815). All air bubbles were removed by placing the mold in a bell jar while the epoxy was still liquid and subjecting it alternately to low pressure (about $1 \mathrm{~cm}$ of $\mathrm{Hg}$ ) and then room pressure (for at least three cycles). The resin was cured by baking overnight at about $55^{\circ} \mathrm{C}$.

${ }^{4} \mathrm{~K}$ arma is the trade name for an alloy (Ni 73 percent, $\mathrm{Cr} 20$ percent+ $\mathrm{Al}+\mathrm{Fe}$ ) having a high resistivity and low temperature coefficient.
The purpose of using this special construction was to get a resistor of minimum inductance which would withstand a high momentary voltage. Minimum inductance was obtained by using two oppositely wound layers connected in parallel and occupying as nearly as possible the same physical space. Sparking between turns and layers was prevented by (1) very uniform spacing and (2) casting in a high dielectric strength resin. The actual resistance and reactance of these units were measured at 0.5 , $2.5,10$, and $30 \mathrm{Mc} / \mathrm{s}$ using a high-frequency bridge (at low voltage). Resistance did not change appreciably over this frequency range, and values of reactance were such that they could be represented by an inductance of $0.2 \mu h$ per unit. Thus, these ribbon-wound cards for the divider high side have a time constant $(L / R)$ of $2 \times 10^{-9}$ sec, which is much less than the minimum figure $\left(10 \times 10^{-9} \mathrm{sec}\right)$ usually given for noninductive high-voltage wirewound resistors.

In order to determine how much voltage could be applied momentarily to these resistors, linearly rising chopped waves of increasing peak value were applied. For chopping times of about $0.7 \mu$ sec each resistor withstood a peak voltage of $60 \mathrm{kv}$, repeated at least 80 times with no apparent damage or change in resistance. For full waves or waves chopped on their tail such high values of peak voltage could not be applied because of the heating effects they might produce in the ribbon material. The instantaneous temperature of the ribbon is determined mainly by the energy $\left[\int i^{2} r d t\right]$ dissipated in the ribbon per shot. Full wave tests on the ribbon resistors indicated that each unit can withstand up to 300 joules on a single shot without damage provided sufficient cooling time is allowed between shots. The momentary resistance change due to this heating was estimated to be less than 0.5 percent because of the low temperature coefficient of Karma. If shots are repeated at 1-min intervals or less, the temperature buildup might cause failure. Whenever a series of shots is to be made, it is advisable to check resisior temperature occasionally between shots.

A set of seven resistors for use as the divider low side $\left(R_{L s}\right.$ in figs. 1 to 6$)$ was made with values from 2.60 to $15.8 \mathrm{ohms}$. This was done so that the CRO peak deflection could always be set, by choosing the proper $R_{L s}$, at some value between 65 and 100 percent of full scale. A cable terminating resistor with taps could not be used at the CRO because of the special method used for cable termination [12].

Each low-side resistor consisted of elements made up of Karma ribbon (1/8 in. wide and 0.001 in. thick) bent back and forth on itself every 2 in. of its length. All bends were pressed flat in a vise. Small strips of mylar insulation (0.001 in. thick) were placed between adjacent 2 -in. lengths of ribbon. All folds were then held tightly together between bakelite blocks and cast in epoxy for permanence. Each complete low-side resistor consisted of one, two, or three of these elements symmetrically placed as closely as possible around a coaxial chassis con- 
nector mounted on a 3 -in. wide copper busbar. All elements were connected in parallel and to the central coaxial terminal. The coaxial terminal provided the connection from the divider low side to the CRO cable. Measurements on these flat ribbon resistors, using a high frequency bridge and frequencies up to $30 \mathrm{Mc} / \mathrm{s}$, indicated that their resistance remains essentially constant up to that frequency. Also their reactance can be represented by a fixed inductance. The time constant of each low-side resistor was measured and found to be about $2.5 \times 10^{-9} \mathrm{sec}$.

\section{Measurement Accuracy}

The main sources of error after eliminating stray pickup, insuring proper cable termination, and correcting for cable attenuation are: (1) the oscillograph and (2) the divider. Repeated checks on the deflection sensitivity of the cold-cathode CRO used in the experimental work indicated that for deflections greater than 65 percent of full scale the accuracy of CRO voltage measurements was within \pm 1 percent. Sweep calibrations obtained by connecting the output of a signal generator (1.5 to 18 $\mathrm{Mc} / \mathrm{s}$ ) to the deflecting plates, indicated that time measurements could be made to within \pm 2 percent of total sweep time. Sweeps with total duration from 0.3 to $40 \mu \mathrm{sec}$ were used. Their linearity was determined using the method described in appendix 8.1 , and in measuring linearity of voltage rise only those sweep sections found to be linear to within 10 percent were used.

Divider errors, which ordinarily introduce the main source of uncertainty in steep-front measurements, depend mostly upon a combination of two effects: (1) stray capacitance from parts of the divider to nearby conducting surfaces and (2) residual inductance in the divider elements. If these two effects are considered separately, a computation can be made of the error introduced by each, based on measured or estimated values. Inductance errors were kept low in the present work by using special ribbon wound resistors as described in the preceding section. Actual values of time constant, as measured for these resistors, were inserted in the formula derived in appendix 8.2 to obtain computed values of error due to stray inductance. This gave an error of 0.5 percent for a rise time of $0.1 \mu$ sec and less error for longer rise times.

An exact computation of stray capacitance errors cannot be so easily deduced because stray capacitance depends on the location of the divider with respect to all nearby conductors. For the divider arrangements used (see figs. 2 to 6 ), all conductors except the laboratory floor and the high voltage lead to the divider were kept at sufficient distance to not affect divider capacitance. The error due to stray capacitance from a vertical divider to the grounded floor plane may be expressed as a time lag $t^{\prime}=R C / 6$, for a linearly rising voltage, as shown by Böckman and Hylten-Cavallius [13]. In this formula $R$ is the total divider resistance and $C$ is the total measured or estimated capacitance to ground. The percent error decreases as the time to measured value increases. Computed values are given in the following table for both the 1,000-ohm (see figs. 2, 3, 4, and 6) and 500-ohm (see fig. 5) divider used in the present work:

\begin{tabular}{|c|c|c|c|c|c|}
\hline \multirow{2}{*}{$\begin{array}{l}\text { Total } \\
\text { divider } \\
\text { resistance }\end{array}$} & \multirow{2}{*}{$\begin{array}{l}\text { Estimated } \\
\text { divider capaci- } \\
\text { tance to } \\
\text { ground }\end{array}$} & \multirow{2}{*}{$t^{\prime}$} & \multicolumn{3}{|c|}{ Percent error for rise times } \\
\hline & & & $0.05 \mu \mathrm{sec}$ & $0.1 \mu \mathrm{sec}$ & $0.5 \mu \mathrm{sec}$ \\
\hline $\begin{array}{r}\text { Ohms } \\
1,000 \\
500\end{array}$ & $\begin{array}{r}\text { Picofarads } \\
22 \\
11\end{array}$ & $\begin{array}{c}\mu . s e c \\
0.00367 \\
.000917\end{array}$ & $\begin{array}{l}-7.4 \\
-1.8\end{array}$ & $\begin{array}{l}-3.7 \\
-0.9\end{array}$ & $\begin{array}{l}-0.7 \\
-0.2\end{array}$ \\
\hline
\end{tabular}

The total stray capacitance error would include not only the component due to capacitance from divider to floor, as listed in the above table, but also a component of opposite sign due to capacitance from divider to its high voltage lead. Thus the total stray capacitance errors would be somewhat lower than those given in the above table.

A comparison of experimental results obtained with the 1,000 and 500-ohm dividers affords a basis for estimating the cancellation effect of the two stray capacitance components. As seen in the above table, flashover voltage measurements obtained with the 1,000-ohm divider would be expected to be several percent lower than those obtained with the $500-\mathrm{ohm}$ divider unless the capacitance from the divider to its high voltage lead compensated for part of the capacitance from divider to ground. Measurements indicated that both dividers gave the same results for all rise times down to about $0.05 \mu \mathrm{sec}$. This indicated that, in the present work, errors due to stray capacitance for rise times greater than $0.1 \mu$ sec were probably not greater than 1 percent.

The above consideration of various possible errors indicates that the values of voltage here reported are accurate to within 1.5 percent for rise times greater than $0.1 \mu$ sec.

\section{Experimental Results}

Linearly rising voltages with various rates of rise obtained as explained in section 3 were used. Waveforms were considered to be linearly rising if the "true variation in rate of voltage rise" $\left(\delta^{\prime}{ }_{R}\right)$ as defined and explained in appendix 8.1 was less than 20 percent. "Rates of voltage rise" were determined by the procedure described in appendix 8.1. Rise times or times to flashover were then obtained by dividing peak voltage at flashover by "rate of voltage rise." Typical examples of the impluse waveforms used are shown in figure 8 . In all cases a negative polarity impluse was applied to the high-voltage electrode. Peak voltages were taken as those measured at the first sudden break in the smoothly rising trace. Other peaks occurring later were assumed to be due to reflection between sphere gap and divider. This is most clearly indicated in figure $8 \mathrm{~K}$ for which the divider was very close to the spheres. Sufficient records, similar to those shown in figure 8, were taken so that complete volt-time curves could be plotted for three different electrodes: (1) $12.5-\mathrm{cm}$ 


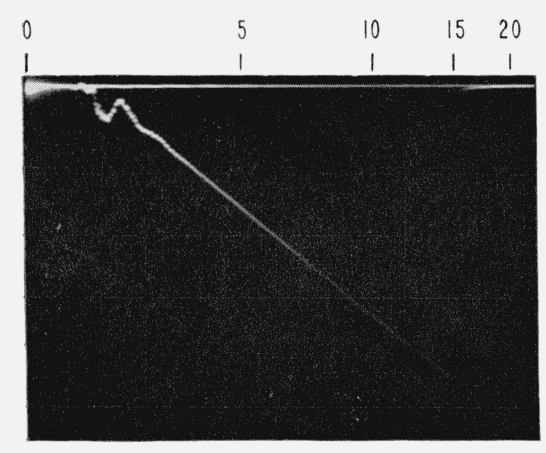

A

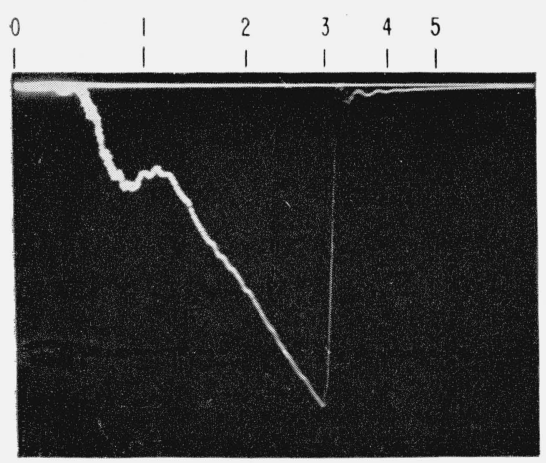

B

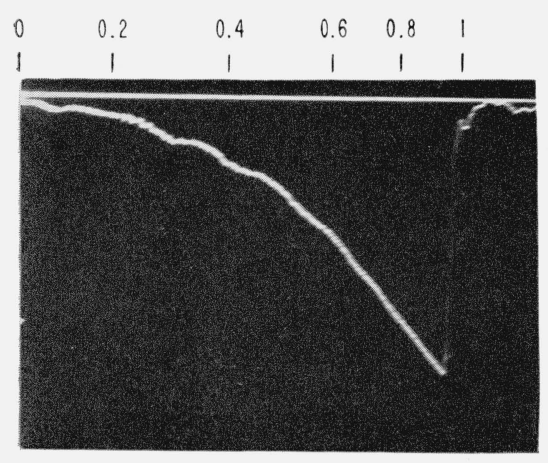

C

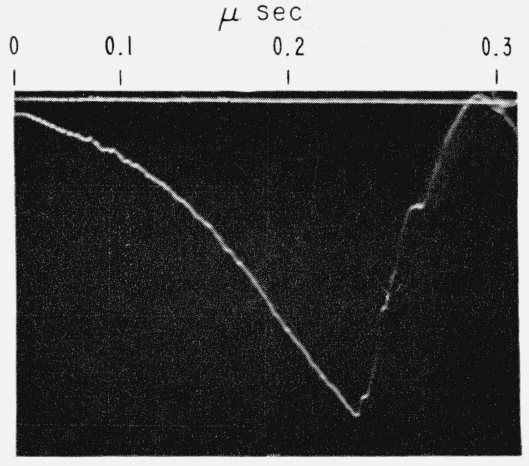

D

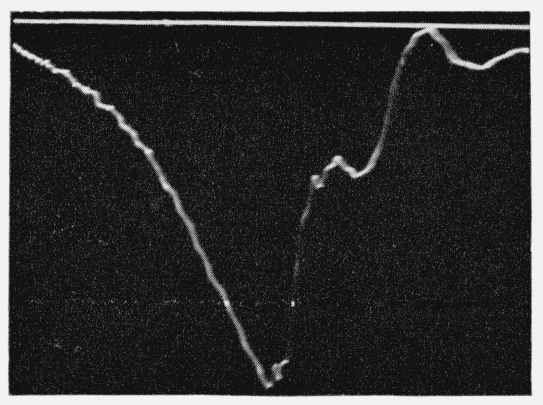

E

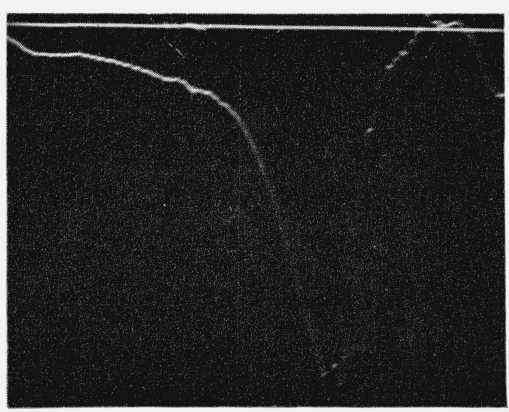

$\mathrm{F}$

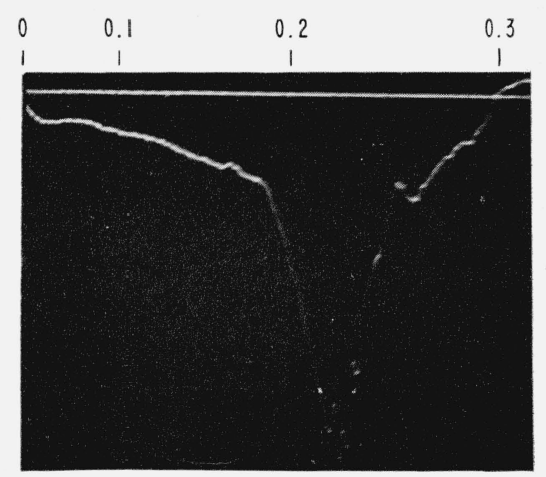

G

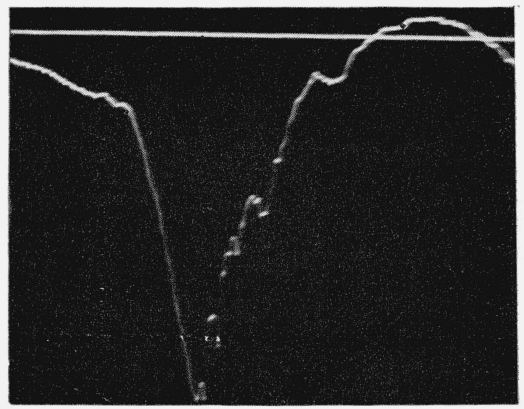

H

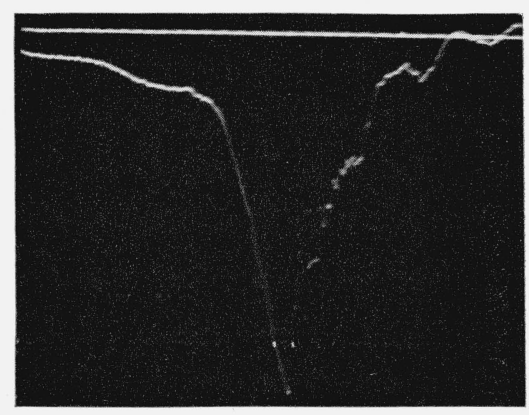

K

FiguRE 8. Typical samples of oscillograms: linearly rising voltages.

\begin{tabular}{|c|c|c|c|c|c|}
\hline & Rise time & Peak & $\begin{array}{l}\text { For divider } \\
\text { setup see }\end{array}$ & $R_{H S}$ & $\mathrm{P}^{\prime \prime}$ \\
\hline & $\begin{array}{l}\mu s e c \\
27\end{array}$ & ${ }^{k v}{ }_{135}$ & Fig. 4_ & $\begin{array}{c}\text { Ohms } \\
1,000\end{array}$ & $20^{\prime \prime}$ \\
\hline $\mathrm{B}$ & 2.7 & 164 & Fig. 2 & 1,000 & $34^{\prime \prime}$ \\
\hline C & 0.86 & 171 & Fig. $4 \ldots$ & 1,000 & $20^{\prime \prime}$ \\
\hline D & .13 & 243 & Fig. $3 \ldots$ & 1,000 & $42^{\prime \prime}$ \\
\hline $\mathrm{E}$ & . 093 & 230 & Fig. $2_{-}$ & 1,000 & $34^{\prime \prime}$ \\
\hline $\mathrm{F}$ & .050 & 277 & Fig. 6 - & 1,000 & $17^{\prime \prime}$ \\
\hline G & .037 & 266 & Fig. 2_ & 1,000 & $34^{\prime \prime}$ \\
\hline $\mathrm{H}$ & .032 & 264 & Fig. $5 \mathrm{~A}$ & 500 & $34^{\prime \prime}$ \\
\hline $\mathrm{K}$ & 046 & 262 & Fig. 5B..... & & \\
\hline
\end{tabular}


diam spheres spaced $6 \mathrm{~cm}$, (2) 25-cm diam spheres spaced $6 \mathrm{~cm}$, and (3) 6.5 -in. (16.5 cm) diam uniform field electrodes spaced $5 \mathrm{~cm}$.

The solid line in figure 2 is the volt-time curve for $12.5-\mathrm{cm}$ spheres spaced $6 \mathrm{~cm}$ apart obtained with the divider arrangement, also shown in figure 2 , and $A$ $=34$ in. The proximity of high voltage conductors of fairly large surface areas, such as parts of the generator or the $1 \mathrm{~m}$ hemispheres used as " $C_{0}$ ", were found to affect flashover voltage. To completely eliminate such effects, the gap was kept $20 \mathrm{ft}$ from any generator or discharge circuit parts while obtaining this curve. It is an average drawn through about 200 plotted points. Each plotted point was obtained from four CRO records repeated at $30-\mathrm{sec}$ intervals. The rates of voltage rise were always nearly identical for each of the four traces in a set. The four values of peak voltage usually agreed to within 1 percent. Plotted points were obtained for various rates of voltage rise over a period of several months and under various laboratory conditions: (1) ambient temperature 22 to $26{ }^{\circ} \mathrm{C}$, (2) atmospheric pressure 748 to $762 \mathrm{~mm}$ of $\mathrm{Hg}$, and (3) relative humidity 42 to 68 percent. All voltages were corrected for relative air density to $760 \mathrm{~mm}$ of $\mathrm{Hg}$ pressure and $25^{\circ} \mathrm{C}$. $[1,2]$. No correlation between humidity and flashover voltage at various rates of rise could be deduced, possibly because the actual range in humidity was not very great. Over 98 percent of the plotted points fell within \pm 2 percent of the solid curve in figure 2 .

Data were also obtained (1) with the horizontal distance between sphere gap and divider changed from 55 in., as shown in figure 2, to 20 in. and (2) using a $500-\mathrm{ohm}$ divider arrangement as shown in figure $5 \mathrm{~A}$ ( $A=34$ in.). Points plotted from these data also fell along the solid curve.

When the distance from the floor to the sphere gap was changed, points did not fall along the same curve. A complete set of data for various rates of voltage rise was obtained for $A=16$ in. (see figs. 2 and 5). The dashed curve plotted using these data is 2 to 3 percent lower than the curve for $A=34$ in. as seen in figure 2.

Some data were also taken using the 500-ohm divider high side and the gap-divider arrangement of figure $5 \mathrm{~B}$. Here the lead from sphere to divider was kept as short as possible which accounts for the sharp break in the CRO record at flashover with no immediate oscillations (see fig. 8K). The oscillations occurring at flashover for some of the other divider arrangements (see figs. $8 \mathrm{G}$ and $8 \mathrm{H}$ ) are probably due to reflection in the lead from sphere to divider. Flashover voltage was always taken as the first break in the linearly rising trace. For the divider arrangement of figure $5 \mathrm{~B}$ the spheres are close to the floor which tends to make flashover voltage low, but the divider and its lead are high voltage conductors fairly close to the sparking point which tend to increase flashover voltage. The observed points fell fairly close to the soild curve in figure 2 showing that these effects tended to cancel each other.

For the purpose of finding a gap arrangement less dependent upon the location of the electrodes with respect to the floor and other nearby conducting surfaces, it was decided to also try $25-\mathrm{cm}$ spheres spaced $6 \mathrm{~cm}$ apart. Using the divider arrangement shown by the insert in figure 3, the volt-time curve plotted in figure 3 was obtained. Procedures used were the same as those already described for $12.5-\mathrm{cm}$ spheres. Proximity effects were studied by (1) changing to the sphere gap and divider arrangement shown in figure 6 (spheres much closer to floor); (2) moving the sphere gap and divider setup closer to the surge generator and the 1-m hemispheres used as $\mathrm{C}_{0}$ (fig. 1), i.e., with the spheres $13 \mathrm{ft}$ from the generator and $3 \mathrm{ft}$ from the nearest hemisphere; and (3) going back to the sphere gap and divider setup shown in figure 3 but with sphere gap close to generator and hemispheres. Data obtained at various rates of voltage rise under all of the above conditions gave points falling along the volt-time curve plotted in figure 3. Thus, as was expected, 25-cm spheres spaced $6 \mathrm{~cm}$ apart afford a more satisfactory volttime curve for use as a reference standard than 12.5$\mathrm{cm}$ spheres spaced $6 \mathrm{~cm}$.

For $60 \mathrm{c} / \mathrm{s}$ and full wave impulses, uniform-ield gaps have been found to give more repeatable flashover voltages than sphere gaps $[14,15]$. It was, therefore, considered advisable to try such gaps on front of wave flashover using linearly rising surges in the same manner as already described for sphere gaps. One pair of 6.5-in diam uniform field electrodes, rated at $140 \mathrm{kv}$ peak, was constructed from solid brass according to the specification given by Bruce [14]. Values of flashover voltage were obtained at an electrode spacing of $5 \mathrm{~cm}$ with various rates of voltage rise. From plotted points using this data the volt-time curve in figure 4 was drawn. Proximity effects were determined by getting data with sparking point both 20 and 40 in. above the floor and with the gap near the generator and hemispheres (3 ft from nearest hemisphere) and at a much greater distance (15 ft from nearest hemisphere). All of these data gave points falling along the curve in figure 4, which indicated that proximity effects were much less than for $12.5-\mathrm{cm}$ spheres spaced $6 \mathrm{~cm}$ but about the same as for $25-\mathrm{cm}$ spheres spaced $6 \mathrm{~cm}$. The scattering of the points about the curve was very nearly the same for uniformfield gaps as for 25 or 12.5 -cm diameter spheres. The main disadvantage of uniform field gaps was found to be the difficulty encountered in getting the electrode axes sufficiently well alined.

All of the data used for plotting the curves in figures 2,3 , and 4 were obtained with a small needle of $\mathrm{Co}^{60}$ (equivalent to $0.5 \mathrm{mr}$ per hour at $1 \mathrm{~m}$ ) placed inside the upper electrode. This was done because Bruce [8] found that full-wave surge breakdown data on spheres had the least scatter when a small amount of radium salt was placed inside one of the spheres. In order to find out if Bruce's conclusion held for breakdown on a linearly rising surge voltage, experimental data were obtained at several different rates of voltage rise with the $\mathrm{Co}^{60}$ removed. The points plotted from these data also fell along the curves, and the repeats from shot to shot were the same as with the $\mathrm{Co}^{60}$ inside the sphere except that 
at slow rates of voltage rise (time to breakdown 8 to $10 \mu \mathrm{sec}$ ) repeats from shot to shot were not quite as good without the $\mathrm{Co}^{60}$. The good repeats obtained without $\mathrm{Co}^{60}$ can be accounted for by radiation from other gaps in the surge generator circuit. When a 12-in. diam cardboard tube was placed around the measuring sphere gap, cutting off this radiation, the plotted points all fell to the right and above the curves; also repeat shots for a fixed rate of voltage rise yielded breakdown voltages differing as much as \pm 10 percent from an average value. These results indicate that a certain minimum ion density between the spheres is needed to obtain repeatable data, but probably radiation from other gaps in the surge generator circuit is sufficient if the measuring gap is not shielded from them. For very low rates of voltage rise (times to breakdown, say, greater than $5 \mu$ sec) the repeatability was definitely not as good as for the higher rates; and it was found advisable to use $\mathrm{Co}^{60}$. An open carbon arc placed $3 \mathrm{ft}$ from the sphere gap was also tried and found to give almost as good repeatability as the $\mathrm{Co}^{60}$ for low rates of voltage rise.

\section{Conclusions}

Special ribbon resistors with low and nearly matched time constants were used to make up the divider high and low sides. From a combination of experimental results and computations based on these resistors, it has been estimated that the results reported are accurate within 1.5 percent.

Data obtained using 12.5 -cm spheres spaced $6 \mathrm{~cm}$ indicated a decrease in flashover voltage of 2 to 3 percent when the distance from laboratory floor to lowest point on upper sphere was decreased from 34 to 16 in. Variations were also noted when high voltage parts of the surge generator and discharge circuit, which have large surface areas, were placed within a radius of $20 \mathrm{ft}$ from the sphere gap. Therefore, when volt-time curves for $12.5-\mathrm{cm}$ spheres spaced $6 \mathrm{~cm}$ (from various laboratories) are being compared, the exact configuration of all conductors within a radius of $20 \mathrm{ft}$ of the spheres should be considered.

For the uniform field gap, proximity effects were found to be negligible at distances greater than $4 \mathrm{ft}$ from the sparking point. Also variations in distance of sparking point above the floor had little or no effect. The repeatability of results from shot to shot and day to day were found to be about the same for the uniform field gap as for sphere gaps. However, adjusting the mounting of the uniform field electrode so that the electrode axes were in accurate alinement was found to be a fairly time-consuming operation. Also uniform field electrodes are not readily obtainable but must be specially made. Because of these disadvantages and since uniform field gaps apparently give no marked decrease in scattering of flashover voltage for a linearly rising impulse, it was concluded that they should not be recommended for setting up a standard volt-time curve.
For 25-cm spheres spaced $6 \mathrm{~cm}$, proximity effects were found to be negligible at distances greater than $4 \mathrm{ft}$ from the sparking point, and the variation in distance of sparking point above the floor made no noticeable change in flashover voltage. Such spheres are probably available in most high voltage laboratories or they can easily be obtained. Therefore, the volt-time curve in figure 3 , for 25 -cm spheres spaced $6 \mathrm{~cm}$, is considered best suited as a reference standard for use in checking the accuracy of steep-front impulse measurements at various laboratories.

\section{Appendix}

\subsection{Definitions for Use in Measuring and Specifying Linearly Rising Impulses}

A CRO with a linear sweep would be most convenient for accurate measurement and tolerance specification because a uniformly rising voltage would be recorded as a straight line, and any departure could be readily detected. If the sweep is not linear, to evaluate uniformity of rate of rise exactly, the voltage trace must be converted to its equivalent with a linear time base by a computing or graphical method. Although most oscillograph sweeps are not exactly linear over their entire range, this rather complicated conversion can be eliminated in most cases by devising a method for evaluating sweep linearity. Then practical limits in sweep nonlinearity can be specified, and particular sweeps or sections of sweeps which exceed these limits should not be used.

\section{a. Determination of Sweep Nonlinearity}

A sweep calibration is obtained by taking an oscillograph record with a suitable high-frequency signal applied to the deflecting system. Data obtained from measurements on this record can then be expressed as a plot of time in microseconds against sweep deflection in inches or centimeters, as illustrated in figure 9 for a typical CRO sweep. For a linear sweep this plot would, of course, be a straight line. Any departure from linearity is indicated by curvature of the plot. The degree of nonlinearity between any two sweep deflections $d_{1}$ and $d_{2}$, corresponding to time $t_{1}$ and $t_{2}$, is determined as follows: draw a straight line tangent to the plot at $d_{2}$ (see fig. 9) and call its intersection with the $d_{1}$ ordinate, $t_{1}^{\prime}$. Sweep nonlinearity in percent, $\delta_{S L}$ is here defined as

$$
\delta_{S L}=\frac{t_{1}-t_{1}^{\prime}}{t_{2}-t_{1}^{\prime}} 100
$$

for the sweep interval from $t_{1}$ to $t_{2}$. $\delta_{S L}$ is positive for $t_{1}>t_{1}^{\prime}$. In general, $\delta_{S L}$ may be either positive or negative; but usually the same sign is maintained throughout any one sweep, and its magnitude is less the shorter the interval $t_{2}-t_{1}$. This definition makes it possible to specify the degree of nonlinearity allowable for various types of measurements and in some cases to apply corrections for nonlinearity. 


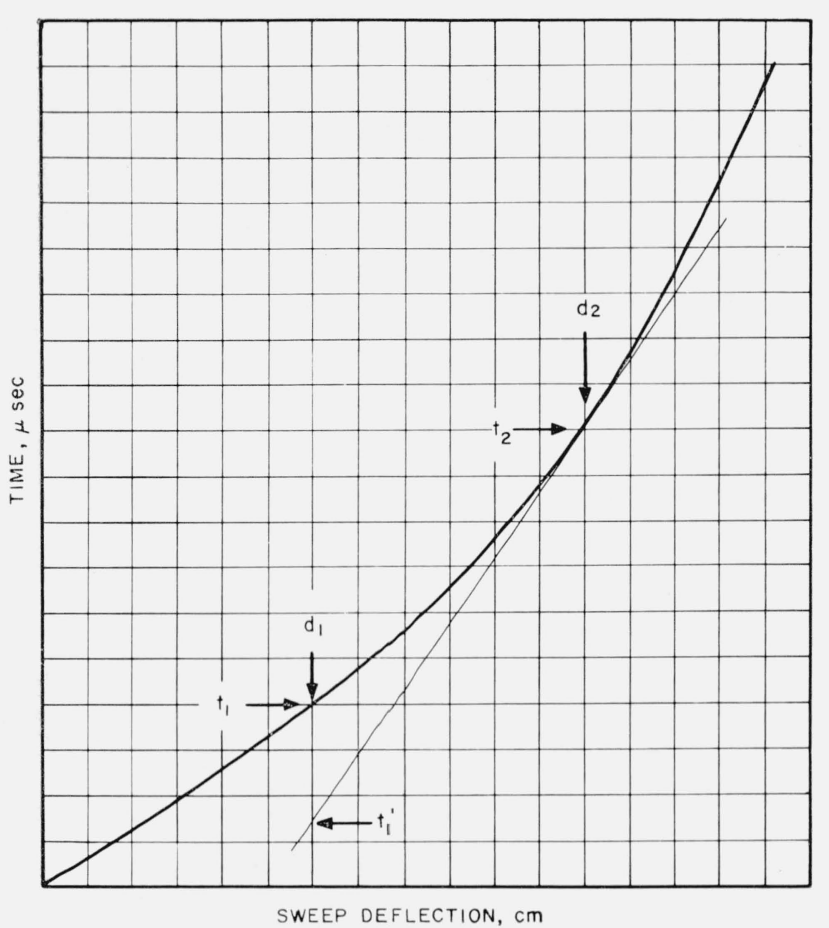

Figure 9. Sweep calibration curve showing method for measuring sweep nonlinearity, $\delta_{S L}$

$$
\delta_{S L}=\frac{t_{1}-t_{1}^{\prime}}{t_{2}-t_{1}}, 100
$$

b. Definitions of Rate of Voltage Rise, Time to Flashover, and Specification of Tolerances

For a linearly rising waveform, the results of sphere gap sparkover data can be presented as a plot of sparkover voltage against either rate of voltage rise or time to sparkover. Since sparkover voltage depends mainly on rate of rise just prior to sparkover, ${ }^{5}$ rate of voltage rise seems the more logical independent variable. However, volt-time curves are already a familiar concept in dielectric breakdown; and since measurement accuracy can best be expressed as a function of rise time, it is thought desirable to use time to sparkover as the independent variable. The definition of "time to sparkover" presents no problem if the voltage rise is exactly linear, but truly linear waveforms are hardly ever attained.

It becomes necessary, therefore, to consider exactly how "time to sparkover" should be determined.

For very short times to sparkover, in order to get repeatable results it is necessary that the rate of voltage rise be very nearly constant over the period of time "just prior to sparkover." It is this rate of rise that determines the magnitude of sparkover voltage. Thus, an equivalent or quasi "time to sparkover" is defined as peak voltage divided by rate

"The term "just prior to sparkover" is intended to mean that portion of the voltage rise between the voltage at which sparkover would occur for a 60 -cycle voltage and the actual value of voltage at which sparkover occurs for the particular wave shape of the applied voltage. It would correspond to the section between $e_{60}$ and $e_{m}$ in figures $10 \mathrm{~A}$ and $10 \mathrm{~B}$.
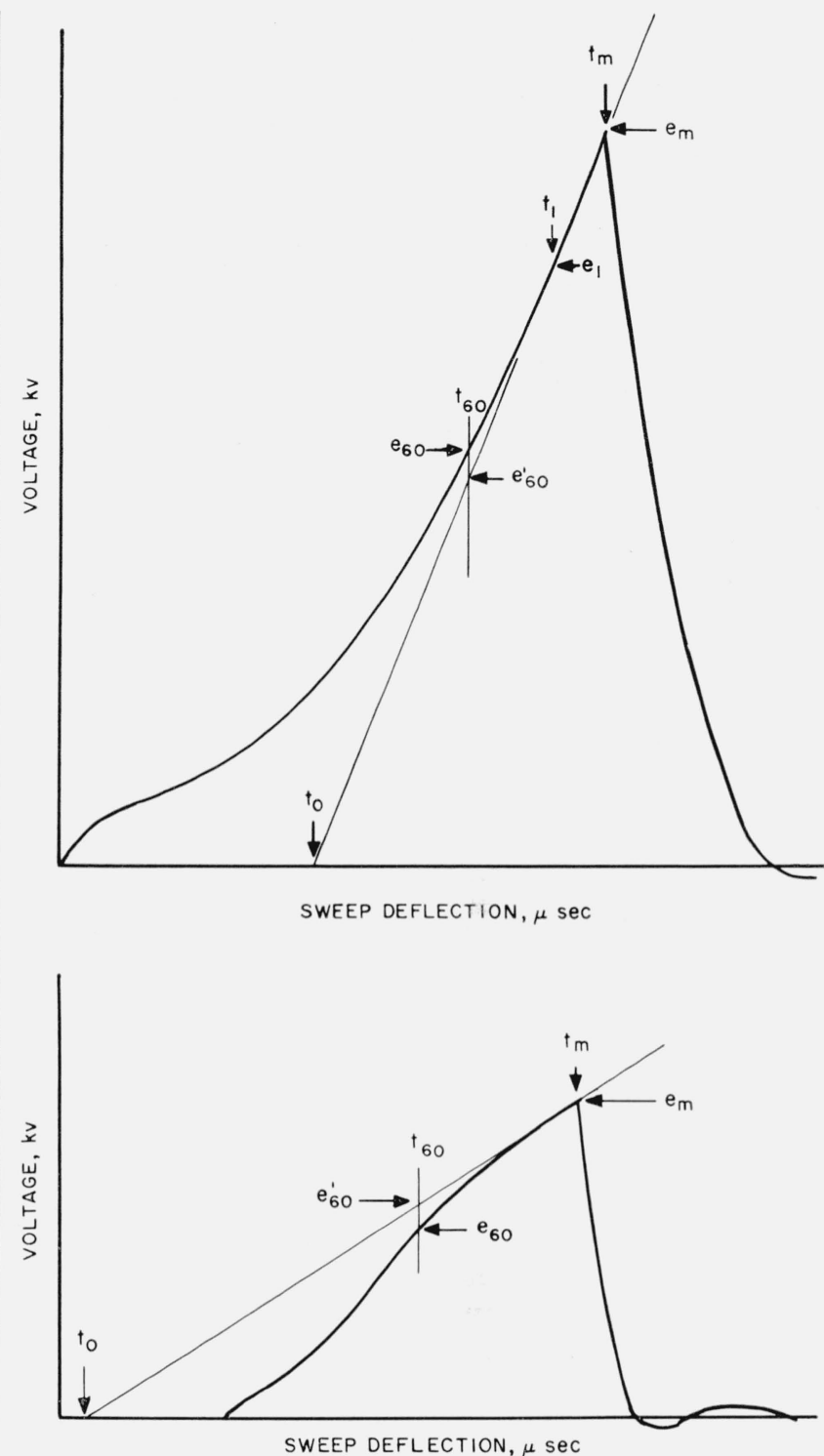

Figure 10. Drawings of oscillograms showing method for measuring rate of voltage rise and variation in rate of rise, $\delta_{l i R}$

$$
\delta_{R R}=\frac{e_{60}-e^{\prime} 60}{e_{m}-e_{60}} 100
$$

(Upper) A. Voltage impulse with very short time to flashover.

(Lower) B. Voltage impulse with longer time to flashover.

of voltage rise just prior to breakdown. To measure this rate of rise, a straight edge is lined up with the section of voltage record from about 80 to 100 percent of the peak or sparkover voltage. For times to sparkover less than $1 \mu \mathrm{sec}$ nearly all acceptable waveforms will fall along the straight edge in this section of the voltage record as indicated in figure $10 \mathrm{~A}$. If there is curvature in this section, which is more likely for times to sparkover greater than 1 $\mu$ sec, the straight edge should be placed tangent to the curve at sparkover voltage as shown in figure 10B. The slope of the straight edge in terms of the 
voltage and time coordinates of the trace is the rate of voltage rise. If the sweep is linear, this slope can be obtained by dividing peak voltage, $e_{m}$, by the time interval between the zero intercept of the straight edge and peak voltage point, $\left(t_{m}-t_{0}\right)$, as shown in figure $10 \mathrm{~A}$. Accuracy requirements are specified by saying that the sweep nonlinearity, $\delta_{S L}$, must be less than 10 percent in the interval used to measure slope, $t_{m}-t_{0}$. Unless this interval is a fairly small fraction of the whole sweep, the 10 percent limit is quite likely to be exceeded. The slope can usually still be obtained to the required accuracy by using a shorter interval such as $\left(t_{m}-t_{1}\right)$ [see fig. 10A] and a smaller corresponding change in voltage, $\left(e_{m}-e_{1}\right)$. These measurements, of course, depend upon the particular sweep being used. It is probably easier to discard voltage traces occurring over sweep intervals with high values of $\delta_{S L}$ than to apply a correction to rate of rise which could be determined from sweep nonlinearity.

In addition to measuring rate of voltage rise just prior to sparkover by the method described, it is also necessary to determine whether rate of rise varies by a significant amount between 30 and 100 percent of sparkover voltage. Experimental data obtained with different wave shapes at the National Bureau of Standards have indicated that as long as the rate of voltage rise is constant from the 60 -cycle peak sparkover value of voltage up to actual sparkover, it is not important that it also remain constant below the 60-cycle peak sparkover value. Thus, between the 30 percent voltage point and 60-cycle sparkover voltage it is only necessary to ascertain that the voltage rises approximately linearly and has no abrupt discontinuities. However, in the range between 60-cycle peak sparkover voltage and actual sparkover, it is necessary to define a "variation in rate of rise" and state tolerances. To do this, $e_{60}$ (see fig. 10A) is taken as the point on the voltage trace corresponding to 60 -cycle peak sparkover voltage. A vertical line through $e_{60}$ intersects the sloping line drawn for measuring rate of rise just prior to flashover at $e_{60}^{\prime}$. Then "variation in rate of voltage rise in percent," $\delta_{R R}$, is defined as

$$
\delta_{R R}=\frac{e_{60}-e_{60}^{\prime}}{e_{m}-e_{60}^{\prime}} 100
$$

This is a true measure of change in rate of rise from point $\left(e_{60}, t_{60}\right)$ to point $\left(e_{m}, t_{m}\right)$ provided the sweep is linear in this range. If the sweep is not linear, constancy of rate of rise would be indicated if $\delta_{R R}=\delta_{S L}$ where both $\delta_{R R}$ and $\delta_{S L}$ are determined for the same time interval $t_{m}-t_{60}$, and their signs are found using the definitions stated. Then the true variation in rate of rise, $\delta_{R R}^{\prime}$, can be defined as

$$
\delta_{R R}^{\prime}=\delta_{R R}-\delta_{S L}
$$

A tolerance is specified by saying that the true variation in rate of rise, $\delta_{R R}^{\prime}$, between the 60 -cycle peak sparkover voltage and actual flashover voltage shall not be greater than 20 percent.
The voltage-time trace shown in figure $10 \mathrm{~A}$ is typical of those obtained for times to sparkover up to about $1 \mu$ sec. For longer times, the curvature of the trace is more likely to be reversed in sign as shown in figure 10B. For very long times to flashover the actual voltage at sparkover approaches the 60 -cycle (full-wave) value, and the tolerances as specified, by using $e_{m}-e_{60}$, allow considerable curvature just prior to flashover. This is not objectionable because flashover voltage changes very slowly with rise time for times greater than $10 \mu$ sec. To insure minimum spread of observed values in this range, it is necessary to irradiate the gap by using an ultraviolet lamp or some radioactive material placed inside one sphere.

\section{c. Summary of Definitions and Tolerances}

The following definitions and methods for expressing tolerances are proposed for use in obtaining sphere-gap volt-time curves from cathode ray oscillograph records.

Sweep nonlinear ity between times $t_{1}$ and $t_{2}$ of an oscillograph record is defined in percentage as

$$
\delta_{S L}=\frac{t_{1}-t_{1}^{\prime}}{t_{2}-t_{1}^{\prime}} 100
$$

where $t_{1}$ is determined as indicated in figure 9 .

Uncorrected variation in rate of voltage rise for a CRO chopped wave voltage trace is defined as the change in rate of rise from point $\left(e_{60}, t_{60}\right)$ to point $\left(e_{m}, t_{m}\right)$ and is given in percentage as

$$
\delta_{R R}=\frac{e_{60}-e_{60}^{\prime}}{e_{m}-e_{60}^{\prime}} 100
$$

where $e_{60}^{\prime}$ is determined as indicated in figure $10 \mathrm{~A}$ or $10 \mathrm{~B}$.

True variation in rate of voltage rise is defined as

$$
\delta_{R R}^{\prime}=\delta_{R R}-\delta_{S L}
$$

where $\delta_{R R}$ and $\delta_{S L}$ are determined using the same time interval.

Linearly rising wavefront is defined as one rising at a constant rate from 30 to 100 percent of flashover voltage.

Allowable tolerances can be fixed by requiring that $\delta_{R R}^{\prime} \leqq 20$ percent, and that between the 30 percent voltage point and 60-cycle sparkover point the voltage shall rise approximately linearly with no abrupt discontinuities.

Rate of voltage rise is defined as the slope of the voltage rise trace just prior to flashover. It is obtained by measuring the slope of a straight edge which has been either (1) lined up with the section of voltage record from 80 to 100 percent of sparkover voltage as indicated in figure $10 \mathrm{~A}$ or (2) placed tangent to the voltage trace at the sparkover point as indicated in figure $10 \mathrm{~B}$. The sweep time interval used in measuring this slope should be chosen so so that $\delta_{S L} \leqq 10$ percent.

Time to flashover is obtained by dividing peak voltage at flashover by rate of voltage rise as defined above. 


\subsection{Inductance Errors of a Resistance Divider Stray Capacitance Neglected}

Suppose a linearly rising voltage $e(t)=m t \quad 1$, is applied across the divider, and

$R_{1}=$ divider high side resistance

$R_{2}=$ divider low side resistance

$R=$ total divider resistance

$L_{1}=$ divider high side inductance

$L_{2}=$ divider low side inductance

$L=$ total divider inductance

$R / L=\alpha$.

The divider low side resistance is assumed to be less than 10 ohms, thus the CRO cable connected in parallel with it can be neglected in a consideration of inductance errors.

The operational equation for finding current through the divider is

$$
(R+p L) i=m t 1 .
$$

The Laplace transform of this equation is

$$
(R+s L) I(s)=\frac{m}{s^{2}}
$$

solving for $I(s)$

$$
I(s)=\frac{m}{L} \frac{1}{s^{2}(s+\alpha)} .
$$

To transform $I(s)$ to a function of time, let

$$
\frac{L}{m} I(s)=f_{1}(s)=\frac{1}{s} f(s), \text { where } f(s)=\frac{1}{s(s+\alpha)} .
$$

Also, the inverse transforms of $f_{1}(s)$ and $f(s)$ are $F_{1}(t)$ and $F(t)$ respectively, thus

$$
F(t)=\frac{1-\epsilon^{-\alpha t}}{\alpha}
$$

and by a well-known theorem in operational calculus

$$
\begin{aligned}
& F_{1}(t)=\int_{0}^{t} F(\tau) d \tau \\
& F_{1}(t)=\int_{0}^{t} \frac{1-\epsilon^{-\alpha \tau}}{\alpha} d \tau .
\end{aligned}
$$

After performing the integration, this expression for $F_{1}(t)$ can be used with eq (1) to obtain

$$
i(t)=\frac{m}{R}\left[t+\frac{L}{R}\left(\epsilon^{-\alpha t}-1\right)\right] .
$$

Using this equation the divider low side voltage,

$$
e_{2}=i R_{2}+L_{2} \frac{d i}{d t}
$$

can be computed as

$$
e_{2}=\frac{R_{2}}{R} m\left[t+\left(\epsilon^{-\alpha t}-1\right)\left(\frac{L}{R}-\frac{L_{2}}{R_{2}}\right)\right] .
$$

The measured value of high side voltage is then

$$
e_{m}=e_{2} \frac{R}{R_{2}}=m\left[t+\left(\epsilon^{-\alpha t}-1\right)\left(\frac{L}{R}-\frac{L_{2}}{R_{2}}\right)\right] \text {. }
$$

The error in measured value due to inductance is

$$
\begin{aligned}
& \delta=\frac{e(t)-e_{m}}{e(t)} \\
& \delta=\frac{\left(1-\epsilon^{-\alpha t}\right)\left(\frac{L}{R}-\frac{L_{2}}{R_{2}}\right) .}{t} .
\end{aligned}
$$

Since $\alpha$ can be easily be made equal to $10^{8}$ or greater, the quantity $\left(1-\epsilon^{-\alpha t}\right)$ is approximately equal to unity for all times greater than $0.05 \mu$ sec. Thus, the error becomes

$$
\delta=\frac{\left(\frac{L}{R}-\frac{L_{2}}{R_{2}}\right)}{t} .
$$

It approaches zero for $\frac{L}{R}=\frac{L_{2}}{R_{2}}$ which is true if $\frac{L_{1}}{R_{1}}=\frac{L_{2}}{R_{2}}$. Therefore, the error can be reduced to a negligible value by making the divider low side time constant nearly equal to that of the higher side.

\section{References}

[1] American standard for measurement of voltage in dielectric tests, AIEE Standard No. 4, ASA C68.1, (1953).

[2] Recommendations for voltage measurement by means of sphere-gaps (one sphere earthed), International Electrotechnical Commission Publication 53, (1960) (Obtainable from ASA Headquarters).

[3] Methods for measurement of voltage with sphere gaps, British Standards Institution-British Standard 358, (1960) $24 \mathrm{pp}$.

[4] P. L. Bellaschi and W. L. Teague, Sphere-gap characteristics on very short impulses, Elec. J. 32, 120 (1935).

[5] J. H. Hagenguth, Short-time sparkover of gaps, Elect. Engr. 56, 67 (1937).

[6] C. J. Miller, Jr., and J. F. Wittibschlager, Measurements of steep-front waves with an isolated screen room installation, AIEE Communication and Electronics Paper 58-18, 262 (1958).

[7] F. C. Creed, The measurement of impulse waves chopped on the front CIGRE Paper 320 (1958).

[8] N. Hyltén-Cavallius, High voltage measuring devices and measuring errors, ASEA Technical Memorandum TM 9184 (1958).

[9] Unpublished report by P. R. Howard of the National Physical Laboratory at CIGRE Meetings in 1958.

[10] Informal results from D. L. Whitehead of Westinghouse Electric Corporation in Pittsburgh.

[11] John H. Park, A fifty-fold momentary beam intensification for a high-voltage cold-cathode oscillograph, J. Research NBS 47, 87 (1951) RP2231.

[12] J. H. Park, Surge measurement errors introduced by coaxial cables, Communications and Electronics, 343, (1958), AIEE Trans. Paper 58-110.

[13] Marius Böchman and Nils Hyltén-Cavallius, Errors in measuring surge voltage by oscillograph, ASEA Ludvika Sweden, (1946).

[14] F. M. Bruce, Calibration of uniform field spark gaps for high voltage measurements at power frequencies, J. IEE (London) 94, pt II No. 38, 138 (1947).

[15] F. M. Bruce, High voltage spark discharges, Endeavour XII, No. 50, 61 (1954).

(Paper 66C3-96) 